\title{
DESENVOLVIMENTO DE FRUTOS DE CIRIGUELEIRA (Spondias purpurea L.) ${ }^{1}$
}

\author{
LAESIO PEREIRA MARTINS², SILVANDA DE MELO SILVA³, RICARDO ELESBÃO ALVES ${ }^{4}$, HELOÍSA ALMEIDA CU- \\ NHA FILGUEIRAS ${ }^{4}$
}

\begin{abstract}
RESUMO- O objetivo dessa pesquisa foi avaliar a curva de desenvolvimento de frutos da cirigueleira. Para a avaliação do crescimento e maturação, as flores foram marcadas após a antese, e as colheitas dos frutos foram realizadas durante todo o período de desenvolvimento, visando às avaliações de diâmetro, comprimento, peso fresco, peso seco e volume. O ciclo de desenvolvimento da antese até o amadurecimento do fruto foi de 124 dias, sendo caracterizado pelo aumento dos pesos fresco e seco, volume, comprimento e diâmetro. O aumento do comprimento do fruto apresentou maior taxa de crescimento até aproximadamente 55 dias, seguido por um período de crescimento mais lento até 105 dias após a antese. O início da maturação do fruto ocorreu quando a taxa de crescimento foi mais lenta, em torno de 100 dias, enquanto o amadurecimento se iniciou aproximadamente aos 119 dias após a antese.
\end{abstract}

Termos para indexação: Índice de maturação, análises físicas, fenologia.

\section{DEVELOPMENT OF RED MOMBIN FRUITS (Spondias purpurea L.)}

\begin{abstract}
The aim of this research was to evaluate the development profile of red mombin fruits. For the evaluation of growth and maturation, open flowers were marked after anthesis and fruits were sampled at regular intervals, and length, diameter, volume, and, fresh and dry weights were measured throughout the development following the growth of the fruits. Red mombin fruit developmental cycle, from anthesis to full ripening, lasted 124 days, characterized by the increase in fresh and dry weights, volume, length, and diameter. The growth period, mainly characterized by the increase in fruit length, had the highest growth rate until approximately 55 days, followed by a lower growth rate period from 55 to 105 days postanthesis. Fruit maturation, which started when fruit growth rates slowed down, was set around 100 days and fruit ripening was initiated around 119 days post-anthesis.
\end{abstract}

Index terms: Maturity indexes, physical analysis, fruit phenology

\section{INTRODUÇÃO}

A cirigueleira (Spondias purpurea L.), originária da América Tropical, produz a ciriguela, fruto tipo drupa de cor vermelho-escura quando maduro, que possui polpa de aroma e sabor agradáveis (Leon \& Shaw, 1990). Devido sua excelente qualidade organoléptica, a ciriguela é muito apreciada no Nordeste brasileiro, refletido pelo contínuo aumento do consumo do fruto in natura ou processado na forma de diversos produtos, normalmente disponibilizados no mercado, o que tem proporcionado crescente interesse para seu cultivo comercial (Sacramento \& Souza, 2000).

O estágio de desenvolvimento dos frutos no momento da colheita tem influência na qualidade do fruto maduro. Quando os frutos são colhidos verdes ou fisiologicamente imaturos, não amadurecem, enrugam e apresentam exsudação da seiva, ou quando o amadurecimento ocorre, a qualidade dos frutos é prejudicada (Hulme, 1970). Os frutos colhidos muito maduros deterioram-se rapidamente, não podendo ser armazenados e/ou comercializados em locais distantes (Kays, 1997). A avaliação do padrão de desenvolvimento de um fruto a partir do florescimento auxilia no estabelecimento de índices de maturidade (Coombe, 1976). Vários critérios têm sido utilizados na determinação da maturidade de frutos, baseados no aspecto aparente (tamanho, diâmetro, cor, etc.) e na composição química (sólidos solúveis, acidez titulável, etc.) do produto na época da colheita. Porém, estes índices podem variar consideravelmente, dependendo do local de cultivo, cultivares e condições climáticas do ano de crescimento (Biale \& Young, 1964). Um dos índices mais utilizados na determinação do ponto de colheita é o número de dias desde a floração até o desenvolvimento pleno do fruto (Warrington et al., 1999).

Muitos trabalhos descrevem as mudanças físicas e químicas durante a maturação, amadurecimento e armazenamento de frutos (Araújo Neto, 2001; Costa, 1998; Díaz-Pérez et al., 1998; Rao et al., 1995; Souza et al., 2000). Nenhum trabalho, no entanto, descreve essas mu- danças em ciriguelas desde o florescimento até o amadurecimento do fruto. O objetivo deste trabalho foi avaliar as mudanças físicas ocorridas durante o ciclo de desenvolvimento de ciriguela, visando a obter subsídios na determinação dos índices de maturação e estabelecimento da fisiologia do fruto e do estádio de maturação mais adequado para a sua colheita e armazenamento.

\section{MATERIAL E MÉTODOS}

A pesquisa foi conduzida durante os meses de agosto a março de 1998-1999 e 1999-2000, no pomar do Centro de Formação de Tecnólogos (CFT), Câmpus IV da Universidade Federal da Paraíba, situado no Município de Bananeiras, zona fisiográfica do Brejo Paraibano. A altitude local é de $552 \mathrm{~m}$, situando-se entre as coordenadas geográficas $6^{\circ} 41^{\prime} 11^{\prime \prime}$ de latitude Sul e $35^{\circ}$ c 37' 41" de longitude Oeste, com clima quente e úmido. A temperatura da região varia entre a máxima de 36 e a mínima de $18{ }^{\circ} \mathrm{C}$, com precipitação média anual de $1200 \mathrm{~mm}$ (Anuário, 1997).

Foram selecionadas ao acaso nove plantas com mais de 5 anos de idade, nas quais foram marcadas as flores abertas (antese), com pedaços de fios de lã de diferentes cores. Imediatamente após a formação do fruto, aproximadamente 3 dias após a antese, foram marcados cerca de 600 frutos/planta, mantidos ainda nas árvores para a avaliação do crescimento e mudança de pigmentação. Com o objetivo de verificar o desenvolvimento dos frutos resultantes das flores marcadas, a partir de 5 dias após a antese e no intervalo de $10 \pm 5$ dias, foram colhidas 3 repetições de 60 ciriguelas. O período total de coleta prolongou-se até os frutos, ainda nas árvores, atingirem o amadurecimento pleno. Após a colheita, os frutos foram conduzidos para o Laboratório de Análise de Alimentos do CFT, para as seguintes avaliações: Peso fresco (g), determinado através de pesagem individual de cada fruto em balança semianalítica; Peso seco (g/100 g de fruto), efetuando-se a secagem em estufa a $70^{\circ} \mathrm{C}$ e pesando-se em balança semi-analítica até atingirem peso constante (AOAC, 1984); Diâmetro e comprimento longitudinal (mm),

\footnotetext{
(Trabalho 197/2001). Recebido: 07/12/2001. Aceito para publicação: 11/12/2002. Parte da Dissertação de Mestrado do primeiro autor. Programa de Pós-Graduação em Agronomia. Centro de Ciências Agrárias (CCA)/ UFPB. Pesquisa financiada parcialmente pelo CNPq.

${ }^{2}$ M.Sc., Dept. de Tecnologia Rural (DTR), Centro de Formação de Tecnólogos (CFT)/UFPB.

${ }^{3}$ Ph.D., Professor Adjunto III, Lab. Biologia e Tecnologia Pós-Colheita, DCFS/CCA/UFPB, C.P.04, 58397-970, Areia- PB. E-mail: silvasil@cca.ufpb.br ;

${ }^{4}$ D.Sc., Pesquisador Embrapa Agroindústria Tropical, C.P. 3761,60511-110, Fortaleza-CE. E-mail: elesbao@cnpat.embrapa.br; heloisa@cnpat.embrapa.br, respectivamente.
} 
determinados através de paquímetro; Volume $\left(\mathrm{cm}^{3}\right)$, sendo o volume de água deslocado pelo fruto, medido através de leitura da graduação da proveta; Cor, determinada a partir de 105 dias após a antese, de acordo com a carta de Munsell (Munsell, 1976), por 10 avaliadores semitreinados. As mudanças na coloração da casca dos frutos, indicativas da transição entre os estádios de maturação, poderão ser acompanhadas pela Figura 4 e Tabela 1, caracterizadas pelos estádios: 1) totalmente verde (TV);2) transição ou breaker (B); 3) início da pigmentação amarela (IP); 4) amarelo predominante (AP); 5) vermelho predominante (VP), e 6) vermelhoescuro (VE) (Tabela 1).

TABELA 1- Mudanças na pigmentação aparente durante a maturação e amadurecimento de frutos em plantas de cirigueleira, de acordo com o grau de cor da casca. Aos 105 dias após a antese, o fruto ligado à planta, embora totalmente verde, encontrava-se completamente formado, enquanto aos 124 dias este apresentava a máxima qualidade para o consumo (Bananeiras-PB, 2000).

\begin{tabular}{|c|c|c|c|c|c|}
\hline \multicolumn{2}{|c|}{$\begin{array}{l}\text { Estádios*/Dias } \\
\text { após Antese }\end{array}$} & \multicolumn{3}{|c|}{ Cor MBC** } & \multirow{2}{*}{$\begin{array}{c}\text { Pigmentação Aparente } \\
\text { Totalmente verde }\end{array}$} \\
\hline 1 & 105 & 7,5 & GY & $4 / 4$ & \\
\hline 2 & 113 & 5 & GY & $5 / 8$ & Breaker \\
\hline 3 & 119 & 2,5 & GY & $7 / 8$ & $\begin{array}{c}\text { Início da pigmentação } \\
\text { amarela }\end{array}$ \\
\hline 4 & 121 & 7,5 & YR & $6 / 10$ & Amarelo predominante \\
\hline 5 & 122 & 5 & YR & $5 / 10$ & Vermelho predominante \\
\hline 6 & 124 & 10 & $\mathrm{R}$ & $14 / 10$ & Vermelho-escuro \\
\hline
\end{tabular}

*Estádios de maturação conforme Figura 4; ** Conforme Munsell Book of Color (Munsell, 1976).

Análise Estatística: O delineamento experimental utilizado foi o inteiramente casualizado. As mudanças ocorridas nos paramêtros físicos, durante o desenvolvimento dos frutos, foram avaliadas através da análise de regressão. Os estádios de maturação, caracterizados através das diferenças entre a coloração dos grupos de frutos, foram classificados após avaliação dos dados pelo teste não paramétrico de Wilcoxon, a pelo menos $5 \%$ de probabilidade.

\section{RESULTADOS E DISCUSSÃO}

Avaliação do padrão de crescimento de frutos de cirigueleira. Nos anos de 1998 e 1999, a floração da cirigueleira no município de Bananeiras-PB, iniciou-se no mês de julho, e a plena floração só foi alcançada nos meses de agosto e setembro. $\mathrm{O}$ ciclo da floração até a colheita (fruto vermelho predominante) compreendeu um período de 124 dias (aproximadamente 17 semanas). A partir do terceiro dia após a abertura dos botões florais (antese), iniciou-se a formação dos frutos (formação da polpa), observando-se, em seguida, um aumento dos pesos fresco e seco, diâmetro, comprimento e volume (Figuras 1; 2; 3 e 4). Aos 105 dias após a antese, o fruto ligado à planta, embora totalmente verde, encontrava-se completamente formado, enquanto aos 124 dias este apresentava a máxima qualidade para o consumo, caracterizada pelo atingimento da cor da casca vermelho-escura brilhante, turgidez e aroma característicos. Quando a maturação foi completada, aproximadamente aos 119 dias após a antese, o fruto necessitou cerca de 5 dias (124 dias após a antese) para o completo amadurecimento na planta. Após 7 dias da maturação completa (126 dias após antese), ocorreu a abscisão de frutos.

Verificou-se aumento significativo $(\mathrm{P}<0,05)$ no volume de ciriguela durante o decorrer do desenvolvimento. $\mathrm{O}$ volume máximo alcançado foi de $13,95 \mathrm{~cm}^{3}$ aos 120 dias após antese (Figura 1), paralelo ao aumento em diâmetro (Figura 3).

Durante o desenvolvimento, os pesos fresco e seco aumentaram segundo modelos lineares. O peso médio dos frutos após ser atingida a maturação plena foi $13,98 \mathrm{~g}$, equivalente a $2,99 \mathrm{~g} / 100 \mathrm{~g}$ de peso seco (Figura 2). O aumento de peso seco acumulado linearmente ao longo do desenvolvimento foi, provavelmente, devido à acumulação de carboidratos (amido e açúcares), como verificado em banana por Lodh et al. (1975). O aumento gradual dos pesos fresco e seco, volume, comprimento e diâmetro, também foi verificado durante o desenvolvimento de tamarindo (Hernández-Unzon \& Lakshminarayana, 1982) e cajá (Costa, 1998)

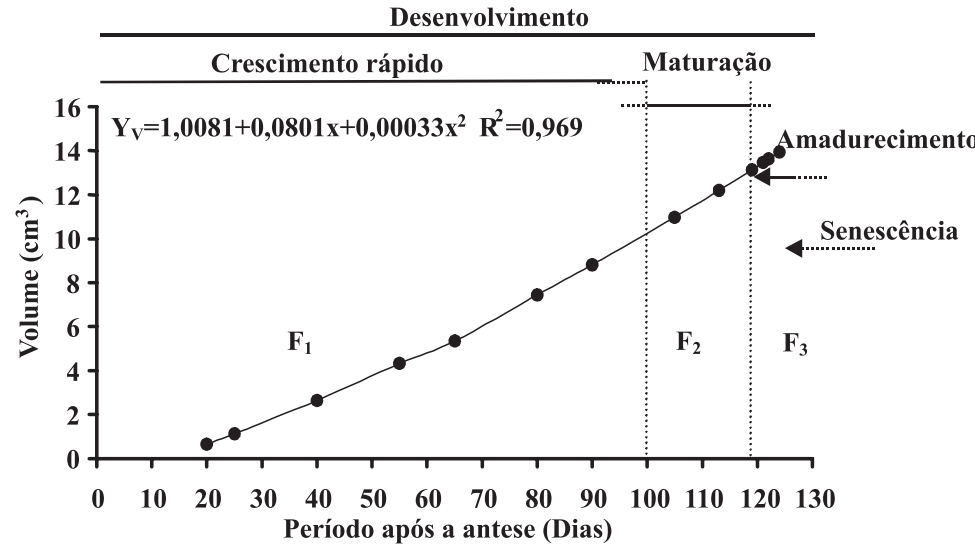

FIGURA 1- Volume de ciriguela durante as fases de crescimento rápido $\left(\mathrm{F}_{1}\right)$, maturação $\left(\mathrm{F}_{2}\right)$ e amadurecimento $\left(\mathrm{F}_{3}\right)$, a partir dos 20 dias após a antese (Bananeiras-PB, 2000).

Desenvolvimento

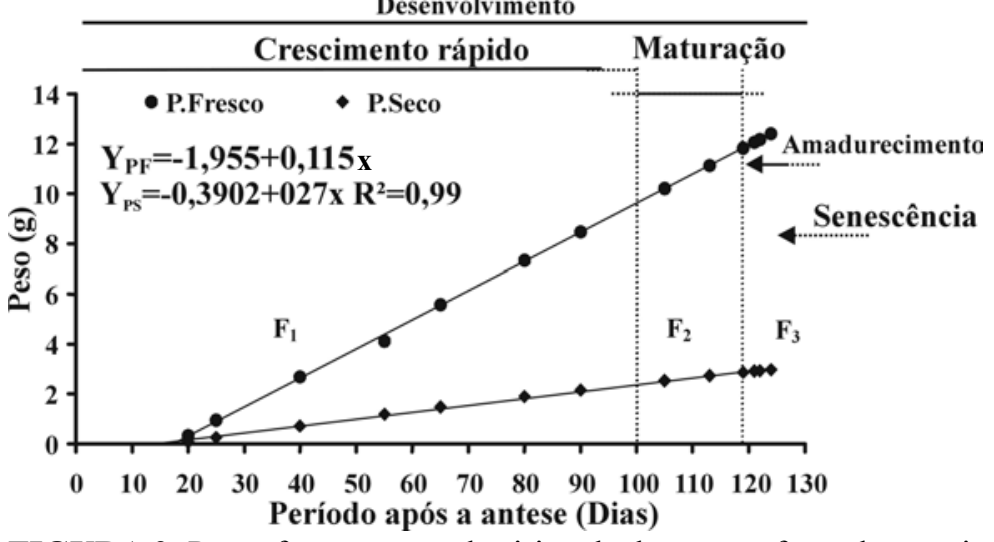

FIGURA 2- Pesos fresco e seco de ciriguela durante as fases de crescimento rápido $\left(\mathrm{F}_{1}\right)$, maturação $\left(\mathrm{F}_{2}\right)$ e amadurecimento $\left(\mathrm{F}_{3}\right)$, a partir dos 20 dias após a antese (Bananeiras-PB, 2000).

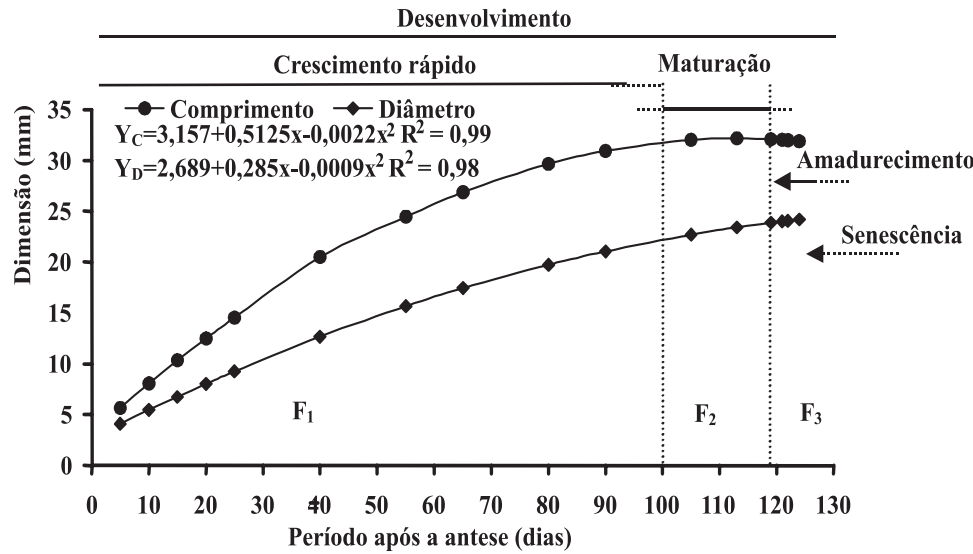

FIGURA 3- Comprimento e diâmetro de ciriguela durante as fases de crescimento rápido $\left(\mathrm{F}_{1}\right)$, maturação $\left(\mathrm{F}_{2}\right)$ e amadurecimento $\left(\mathrm{F}_{3}\right)$, a partir dos 5 dias após a antese (Bananeiras-PB, 2000).

Os frutos atingiram comprimento máximo $(32,17 \mathrm{~mm})$ aos 105 dias após a antese (Figura 3). O diâmetro máximo (24,73 mm), no entanto, foi atingido aos 119 dias após a antese, correspondendo assim à fase conhecida como enchimento dos frutos. O comprimento e o diâmetro de ciriguela tiveram aumento quadrático.

O padrão de desenvolvimento acumulativo de ciriguela seguiu um modelo de crescimento sigmoidal simples (Figuras 1 e 3), representando um crescimento inicial rápido $\left(\mathrm{F}_{1}\right)$, seguido de um crescimento lento $\left(\mathrm{F}_{2} \mathrm{e} \mathrm{F}_{3}\right)$, padrão este também reportado para maçã e laranja 
(Gortner et al., 1967; Awad, 1993). A curva de desenvolvimento de ciriguela, portanto, pode ser dividida em três fases: na fase $\mathrm{I}\left(\mathrm{F}_{1}\right)$, o crescimento propriamente dito estendeu-se até aproximadamente 100 dias após a abertura da flor. Nesse período, quando avaliado pelo aumento de comprimento e diâmetro, observou-se crescimento mais rápido até aproximadamente 55 dias, seguindo-se um período de desaceleração até os 105 dias, certamente resultante do processo de expansão celular (Coombe, 1976), atingindo diâmetro e comprimento máximos a taxas mais lentas de crescimento em torno dos 113 dias após a antese. $\mathrm{O}$ crescimento primário de frutos é devido principalmente a um aumento em volume da célula (Hulme, 1970). O volume de ciriguela aumentou continuadamente durante todo o período de desenvolvimento, resultando, principalmente, do aumento do comprimento e diâmetro do fruto na fase $F_{1}$. Nas fases $F_{2}$ e $F_{3}$, no entanto, $o$ aumento de volume parece ter tido maior contribuição do aumento dos pesos fresco e seco, decorrente da acumulação de açúcares (dados não mostrados). $\mathrm{O}$ aumento do volume do fruto foi proporcionado pelo aumento do número e tamanho das células, as quais inicialmente se acham constituídas de protoplasmas e, na seqüência do crescimento, ocorrendo a formação dos vacúolos e acúmulo de carboidratos e outros compostos (Gortner et al., 1967). Em cajá (Spondias mombin), a partir do final do período de crescimento rápido, quando ocorre intensa atividade meristemática, inicia-se a formação dos tecidos intraloculares ou polpa (Lozano, 1986). Durante o desenvolvimento de peras, Mitchell (1986) refere-se à existência de uma relação entre volume e peso. Em ciriguela, a fase de crescimento mais intenso $\left(\mathrm{F}_{1}\right)$ foi caracterizada pelo aumento do volume dos frutos, acompanhado pela pigmentação verde-intensa, características estas indicativas da atividade celular máxima, refletida pela imaturidade fisiológica. Em geral, a divisão celular está restrita à primeira e segunda fases do desenvolvimento, podendo ser, para alguns frutos, como o tomate, de curta duração (Hulme, 1970; Awad, 1993), ou prolongando-se também por várias semanas, como em carambola (González et al., 2001). A expansão celular, por outro lado, pode continuar até a maturidade (Gortner et al., 1967; Rao et al., 1995).

A fase II $\left(\mathrm{F}_{2}\right)$, a maturação, estendeu-se de aproximadamente 100 aos 119 dias após a antese e foi caracterizada por uma desaceleração da taxa de crescimento, onde os frutos apresentaram taxas mais baixas de aumento de comprimento e diâmetro, e acúmulo de pesos fresco e seco (Figuras 2 e 3). O aumento do volume do fruto, nesta fase, ocorreu de forma discreta, mediante o aumento conjunto do comprimento e diâmetro. Nesta fase intermediária do desenvolvimento, ciriguelas atingiram o comprimento máximo aos 105 dias após a antese.

A fase III $\left(\mathrm{F}_{3}\right)$, do desenvolvimento, iniciou-se em torno de 119 dias após a antese e foi caracterizada pela taxa de crescimento mais lento do fruto, quando ocorreu o início do amadurecimento. $\mathrm{O}$ amadurecimento pleno, dando início aos sinais de enfraquecimento da camada de abscisão do pecíolo como preparação para a liberação do fruto da planta, ocorreu aos 125 dias após antese. Nessa fase, os frutos já haviam completado o desenvolvimento e atingido a máxima qualidade comestível, caracterizada por profundas modificações na textura e nos pigmentos, refletida pela transição da cor verde-escura para vermelho-escura, no decorrer de 25 dias entre a maturação e amadurecimento (Figura 4; Tabela 1).

Baseada nas mudanças da cor da casca (Figura 4 e Tabela 1), a avaliação dos frutos das cirigueleiras mantidos na planta, desde a maturação até o amadurecimento, permitiu caracterizar a transição dos seis estádios de maturação, nos quais ocorrem as principais transformações dos frutos. Nas condições deste estudo, na microrregião do Brejo Paraibano, verificou-se que, para frutos ligados à planta, o estádio totalmente verde (TV) torna-se 'breaker' (B) em oito dias; frutos no estádio B atingem o estádio onde ocorre o ínicio da pigmentação amarela (IP) em seis dias; do IP para o estádio onde a coloração dos frutos torna-se amarelo predominante (AP) são dois dias; a transição do estádio AP para o vermelho predominante (VP) ocorre em apenas 1 dia; e do VP para o estádio onde o fruto é vermelho-escuro (VE) são dois dias de amadurecimento.

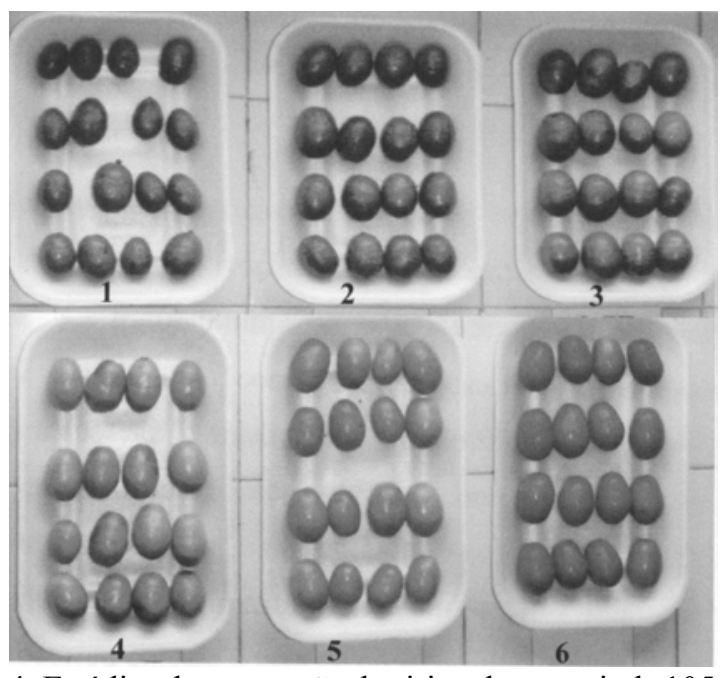

FIGURA 4- Estádios de maturação de ciriguela, a partir de 105 dias após a antese, conforme descrito na Tabela 1. 1-Totalmente Verde (TV); 2-Breaker (B); 3-Início da Pigmentação Amarela (IP); 4-Amarelo Predominante (AP); 5-Vermelho Predominante (VP); 6- Vermelho-Escuro (VE).

\section{CONCLUSÕES}

1) Os pesos fresco e seco aumentaram linearmente a partir da antese até $\mathrm{o}$ amadurecimento.

2)O comprimento e diâmetro dos frutos aumentaram quadraticamente durante a fase de crescimento e maturação.

3) O volume do fruto aumentou quadraticamente durante as fases de crescimento, maturação e amadurecimento.

4) O ciclo de desenvolvimento de ciriguela, a partir da abertura da flor até o amadurecimento do fruto, corresponde a um período médio de 124 dias.

5) Na região do Brejo Paraibano, a maturação de ciriguela iniciou-se ao redor de 100 dias e o amadurecimento aos 119 dias após a antese.

\section{REFERÊNCIAS BIBLIOGRÁFICAS}

ANUÁRIO ESTATÍSTICO DO BRASIL, 1996. Rio de Janeiro: IBGE, 1997. v. 57,1096 p.

ARAÚJO NETO, S.E.; PRAÇA, E.F.; CARVALHO, E.F.; ALVES, R.E.; MENEZES, J.B.; MORAIS, E.A. Desenvolvimento do fruto do sapotizeiro (Manilkara achras (Mill.) Fosberg). Revista Brasileira de Fruticultura, Jaboticabal-SP, v. 23, n.1, p. 025-029, 2001.

ASSOCIATION OF OFFICIAL ANALYTICAL CHEMISTS-AOAC. Official methods of analysis of the Association of Official Analytical Chemists.12.ed, Washington, 1984. 1094p.

AWAD, M. Fisiologia pós-colheita de frutos. São Paulo: Nobel, 1993. $114 p$.

BIALE, J.B.; YOUNG, R.E. Growth, maturation and senescence in fruits. Science, Washington, v. 146, n. 3646, p. 880-888, 1964.

COOMBE, B.G. The development of fleshy fruits. Annual Review of Plant Physiology, Palo Alto, v. 27, p. 507-528, 1976.

DÍAZ-PÉREZ, J.C.; ZAVALETA, R.; BAUTISTA, S.; SEBASTIÁN, V. Cambios físico-químico de ciruela mexicana (Spondias purpurea L.) cosechada en dos diferentes estados de madurez. Revista Iberoamericana de Tecnología Postcosecha, Cidade do México, v.1, n.1, p.20-25, 1998 .

GONZÁLEZ, D.V.; HERNÁNDEZ, M.S.; HERRERA,A.; BARRRERA, J.A.; MARTINEZ, O.W.; PAEZ, D. Desarrollo del fruto e indices de cosecha de la carambola (Averrhoa carambola L.) producida en el Piedemonte Amazonico Colombiano. Revista Iberoamericana de Tecnología Postcosecha, Cidade do México, v.3, n.2, p.144-154, 2001.

GORTNER, W.A.; DULL, GG, KRAUSS, B. H. Fruit development, maturation, 
ripening, and senescence: A biochemical basis for horticultural terminology. HortScience, Alexandria, v. 2, n. 4, p. 141-144, 1967.

HERNÁNDEZ-UNZON, H,Y.; LAKSHMINARAYANA, S. Developmental physiology of tamarind fruit (Tamarindus indica L.). HortScience, Alexandria, v.17, n.6, p.938-940, 1982.

HULME, A.C. The Biochemistry of fruits and their Products. London: Academic Press, 1970.618p.

KAYS, S.J. Postharvest physiology of perishable plant products. Athens: Avi, 1997. 532p.

LEON, J.; SHAW, P. E. Spondias: the red mombin and releated fruits. In: NAGY, S.; SHAW, P.E.; WARDOWSKI, W.F.(Ed.). Fruits of tropical and subtropical origin, composition, properties and uses. Lake Alfred, Flórida, Florida Science Source, 1990. p. 116-126.

LODH, S.B.; RAVEL, P.; SELVARAJ, Y.; KOHLI, R.R. Biochemical changes associated with growth and development of 'Dwarf Cavendish' banana. In: PANTASTICO, E.B. (Ed.).Posthavest physiology, handling and utilization of tropical and subtropical fruits and vegetables. Westport:AVI, 1975. p.560.

LOZANO, N.B. Desarrollo y anatomia del fruto del jabo (Spondias mombin L.). Caldasia, Bogotá, v. 14, n. 68-70, p. 465-490, 1986.
MITCHELL, P.D. Pear fruit growth and use of diameter to estimate fruit volume and weight. HortScience, Alexandria, v.21, n.4, p. 1003-1005, 1986.

MUNSELL, A.H. Munsell book of color. v.2. Baltimore: Munsell Color Company, 1976. np. RAO, M.M.; ROKHADE, A.K.; SHANKARANAYANA, H.N.; PRAKASH, N.A.; SULLADMATH, V.V.; HITTALMANI, S.V. Developmental patterns and duration of growth and development of some tropical and sub-tropical fruits under mild tropical rainy climate. Mysore Journal of Agricultural Sciences, Dharwar, Índia. v. 29, n. 2, p. 149-154, 1995.

SACRAMENTO, C.K.; SOUSA, F.X. Cajá (Spondias mombin L.). FUNEP, Jaboticabal. 2000. 52p. (Série Frutas Nativas, n. 4).

SOUSA, R. P.; FILGUEIRAS, H.A.C.; COSTA,J.T.A; ALVES, R.E.A.; OLIVEIRA, A.C. Armazenamento da ciriguela (Spondia purpurea L.) sob atmosfera modificada e refrigeração. Revista Brasileira de Fruticultura, Jabuticabal-SP, v. 22, n. 3, p. 334-338, 2000.

WARRINGTON, L.J.; FULTON, T.A.;HALLIGAN, E.A. SILVA, H.N. Apple fruit growth and maturity are affected by early season temperatures. Journal American Society Horticultural Science, Alexandria, v.124, n.5, p. 468-477, 1999. 